CLINICAL STUDY

\title{
Cardiovascular risk, metabolic profile, and body composition in adult males with congenital adrenal hyperplasia due to 21-hydroxylase deficiency
}

\author{
Henrik Falhammar ${ }^{1,2}$, Helena Filipsson Nyström ${ }^{3}$, Anna Wedell ${ }^{2}$ and Marja Thorén ${ }^{1,2}$ \\ ${ }^{1}$ Department of Endocrinology, Metabolism and Diabetes, and ${ }^{2}$ Department of Molecular Medicine and Surgery, Karolinska University Hospital and \\ Karolinska Institutet, SE-171 76 Stockholm, Sweden and ${ }^{3}$ Department of Endocrinology, Sahlgrenska University Hospital and Sahlgrenska Academy, \\ University of Gothenburg, Göteborg, Sweden \\ (Correspondence should be addressed to H Falhammar at Department of Endocrinology, Metabolism and Diabetes, Karolinska University Hospital and \\ Karolinska Institutet; Email: henrik.falhammar@ki.se)
}

\begin{abstract}
Objective: Lifelong glucocorticoid therapy in patients with congenital adrenal hyperplasia $(\mathrm{CAH})$ or the disease per se may result in increased cardiovascular risk. We therefore investigated cardiovascular and metabolic risk profiles in adult CAH males.

Subjects and methods: We compared CAH males $(n=30), 19-67$ years old, with age- and sex-matched controls $(n=32)$. Subgroups of different ages $(<30$ years or older) and CYP21A2 genotypes (null, I2splice, and I172N as the mildest mutation) were studied. Anthropometry, fat and lean mass measured by dual-energy X-ray absorptiometry, lipids, liver function tests, homocysteine, lipoprotein(a), glucose and insulin during an oral glucose tolerance test (OGTT), urine albumin, adrenal hormones, and $24 \mathrm{~h}$ ambulatory blood pressure measurements were studied.

Results: CAH males were shorter. Waist/hip ratio and fat mass were higher in older patients and the I172N group. Heart rate was faster in older patients, the I2splice, and I172N groups. Insulin levels were increased during OGTT in all patients and in the I172N group. $\gamma$-glutamyl transpeptidase was increased in older patients and in the $1172 \mathrm{~N}$ group. Testosterone was lower in older patients. Homocysteine was lower in younger patients, which may be cardioprotective. The cardiovascular risk seemed higher with hydrocortisone/cortisone acetate than prednisolone. Urinary epinephrine was lower in all groups of patients except in $\mathrm{I} 172 \mathrm{~N}$.

Conclusions: Indications of increased risk were found in CAH males $\geq 30$ years old and in the I172N group. In contrast, younger CAH males did not differ from age-matched controls. This is likely to reflect a better management in recent years.
\end{abstract}

European Journal of Endocrinology 164 285-293

\section{Introduction}

Congenital adrenal hyperplasia $(\mathrm{CAH})$ causes adrenal androgen excess and varying extent of cortisol and aldosterone deficiency. More than $95 \%$ of cases are due to 21-hydroxylase deficiency and three phenotypes are recognized (1). There are two classic forms, the saltwasting form (SW) manifested neonatally by severe salt loss, and the simple virilizing form (SV) where salt loss is mild or absent. The nonclassic (NC) variant is usually diagnosed with hyperandrogenism later in childhood or adulthood with most males being identified in the course of family investigations (1). There is generally a good phenotype-to-genotype correlation (2), and genotypes may predict outcomes better than phenotypes (3-7).

The consequences of having $\mathrm{CAH}$ throughout adult life are incompletely investigated and there are circumstances with the potential to bring about increased cardiovascular morbidity and mortality. Glucocorticoids, the foundation of $\mathrm{CAH}$ treatment, is often given in supraphysiological doses to normalize the adrenal androgens, which may lead to unfavorable metabolic consequences: obesity, insulin resistance with type 2 diabetes (T2DM), and hypertension. Longstanding undertreatment with elevation of adrenal androgens may also reduce insulin sensitivity $(8,9)$ and induce hypogonadism with low testosterone values by gonadotropin suppression. Hypogonadotropic hypogonadism has been shown to be a risk factor for the metabolic syndrome and T2DM and to increase cardiovascular mortality (10). Inadequate mineralocorticoid therapy for aldosterone deficiency may also have negative impact on the vascular system (11). Previous reports on cardiovascular and metabolic profiles in $\mathrm{CAH}$ adults have mainly included young females, in spite of the fact that males in general have a higher 
cardiovascular risk, and the results have been contradictory $(6,8,9,11-22)$. A very recent publication described however a cohort of 203 individuals with $\mathrm{CAH}$ including 62 males reporting adverse metabolic profiles (23).

The aim of this study was to investigate cardiovascular and metabolic parameters in more detail in adult $\mathrm{CAH}$ males and to compare them with age- and sex-matched controls. Younger and older patients, and different CYP21A2 mutations were compared to disclose potential changes associated with age and genotype.

\section{Subjects and methods}

\section{Subjects}

Adult CAH males with genetically confirmed diagnosis were recruited mainly from the two participating University Hospitals. The data were divided into the subgroups aged $<30$ years or older to allow comparisons with previous studies that had mainly included males below 30 years $(9,14,16,17,19,21)$. Moreover, pediatric endocrinology was introduced in Sweden about 30 years before the inclusion of the present cohort, which could affect outcomes.

Data were also divided according to the three most prevalent CYP21A2 mutations: null, I2splice, and I172N. Null refers to mutations completely abolishing enzyme activity and is associated with the SW phenotype. I2splice retains a very low, but measurable, level of activity and is usually associated with SW, whereas $1172 \mathrm{~N}$ is milder and most often found in SV patients.

Control subjects, one for each patient, were recruited by asking subsequent males in the National Population Registry to participate. They were born on the same date as the patient and most of them were living in the same area. The only exclusion criterion used was severe mental or psychiatric disturbance with inability to consent to the study.

The study was approved by the Ethic Committee of the Karolinska Institute, Stockholm, and the University of Gothenburg, Göteborg, Sweden. All participants gave their written informed consent.

\section{Study protocol}

Patients and controls were examined as outpatients at the Department of Endocrinology, Metabolism, and Diabetes, Karolinska University Hospital, Stockholm $(n=42)$ or the Department of Endocrinology, Sahlgrenska University Hospital, Göteborg $(n=20)$, Sweden. Measurements included height, weight, and waist and hip circumference. Body mass index (BMI) was calculated $\left(\mathrm{kg} / \mathrm{m}^{2}\right)$. Total and regional fat and lean mass were studied by dual-energy X-ray absorptiometry (DXA). Ambulatory blood pressure and heart rate during $24 \mathrm{~h}$ were measured. Blood samples were collected after an overnight fast followed by an oral glucose $(75 \mathrm{~g})$ tolerance test (OGTT). A morning urinary spot sample was collected for albumin. Urinary catecholamines were collected during $24 \mathrm{~h}$. In patients, $24 \mathrm{~h}$ urinary pregnanetriol and a diurnal 17-hydroxyprogesterone (170HP) curve (0800, 1400, 1900, 0100, and $0600 \mathrm{~h})$ using dried blood spots were analyzed.

\section{Glucocorticoid supplementation}

Glucocorticoids were converted to hydrocortisone equivalents using anti-inflammatory equivalents (30 $\mathrm{mg}$ hydrocortisone $=37.5 \mathrm{mg}$ cortisone acetate $=$ $7.5 \mathrm{mg}$ prednisolone $=0.75 \mathrm{mg}$ dexamethasone) (24). Body surface area was calculated as the square root of (height $(\mathrm{cm}) \times$ weight $(\mathrm{kg})) / 3600\left(\mathrm{~m}^{2}\right)$ and was used to indicate hydrocortisone equivalents in $\mathrm{mg} / \mathrm{m}^{2}$.

\section{Methods}

Body composition was estimated by DXA (Lunar Model Prodigy equipment; Lunar Radiation, Madison, WI, USA). The two instruments were calibrated. Lean and fat mass were adjusted for body height $\left(\mathrm{kg} / \mathrm{m}^{2}\right)$. Ambulatory $24 \mathrm{~h}$ blood pressure and heart rate were determined with Meditech ABPM-05 (Meditech Ltd, Budapest, Hungary).

\section{Biochemical assays}

Plasma renin was measured by IRMA (Nichols Institute Diagnostics, San Clemente, CA, USA). Serum cholesterol, triglycerides, high-density lipoprotein (HDL), alanine aminotransferase (ALT), $\gamma$-glutamyl transpeptidase (GGT), alkaline phosphatase (ALP), lipoprotein-(a) $(\mathrm{Lp}(\mathrm{a}))$, and plasma homocysteine and glucose were measured on SYNCHRON LX Systems (Beckman Coulter, Inc., Fullerton, CA, USA). The low-density lipoprotein (LDL) concentration was calculated (25). Serum insulin, testosterone, sexual hormone binding globulin (SHBG), and dried blood spot 170HP were measured by fluoroimmunoassay (AutoDelfia, PerkinElmer, Waltham, MA, USA). Urinary pregnanetriol was determined by gas chromatography and gas chromatography-mass spectrometry. HPLC was used for determinations of $24 \mathrm{~h}$ urinary epinephrine, and norepinephrine, and $\mathrm{HbA1c}$, the latter by the MonoS method (ref. 3.6-5.3\%). Urinary albumin was measured using routine assay.

\section{Statistical analysis}

Data were analyzed using SigmaStat for Windows (Jandel Scientific, Erkarath, Germany). Results are presented as the mean \pm s.D. if not otherwise stated. 
Comparisons between the two groups were made using the unpaired $t$-test when values were normally distributed. Otherwise, the Mann-Whitney rank-sum test was used and, in these cases, the median and range are reported. When continuous variables were compared in the three groups, one-way ANOVA was used for normal distributions followed by post hoc Bonferroni t-test, otherwise the Kruskal-Wallis test, followed by post hoc Mann-Whitney rank-sum test with Dunn's method, was performed. $\chi^{2}$ was used in frequency table calculations or, when the expected frequency was small $(<5)$, Fisher's exact test. All proportions were calculated discounting missing values. Linear and multiple correlations were used for correlation analyses. Statistical significance was set at $P<0.05$ and trend at $0.05-0.10$.

\section{Results}

\section{Characteristics of the patients}

The included patients were aged 19-67 (35.7 \pm 11.4$)$ years. Nine patients were <30 $(23.4 \pm 3.3)$ years and $21 \geq 30(40.9 \pm 10.3)$ years. All 17 patients with the SW phenotype were diagnosed during the first weeks of life (null, $n=7$; I2splice, $n=9 ; \mathrm{I} 172 \mathrm{~N}, n=1$ ) and the 11 patients with the SV phenotype at 3-28 years of age (I172N, $n=8$; I2splice, $n=2$; P453S, $n=1$ ). One of them, a 29-year-old male (I172N) was recently diagnosed and used no medication; S-170HP was $900 \mathrm{nmol} / \mathrm{l}$. Two patients had NC phenotype; a 45-year-old male (V281L) diagnosed at age 30 used prednisolone when acutely ill; a 31-year-old male (P105L+P453S) diagnosed at the start of puberty took prednisolone and fludrocortisone.
Thus, 93\% $(n=28)$ received glucocorticoids most commonly prednisolone $(61 \%)$, or hydrocortisone $(18 \%)$. The mean dose in hydrocortisone equivalents was $17.4 \pm 5.2 \mathrm{mg} / \mathrm{m}^{2}$ without differences between younger and older patients $(16.5 \pm 3.8$ vs 17.7 $\pm 5.6 \mathrm{mg} / \mathrm{m}^{2} ; P=\mathrm{NS}$ ) or genotype groups. The distribution of different glucocoticoids in the subgroups were $<30$ years of age: prednisolone $n=6$, combination of prednisolone and hydrocortisone $n=1$, dexamethasone $n=1$; $\geq 30$ years of age: prednisolone $n=13$, hydrocortisone $n=5$, cortisone acetate $n=2$; the null group: prednisolone $n=5$, hydrocortisone $n=1$, cortisone acetate $n=1$; the I2splice group: prednisolone $n=7$, hydorcortisone $n=2$, dexamethasone $n=1$; the $1172 \mathrm{~N}$ group: prednisolone $n=5$, hydrocortisone $n=2$, combination of prednisolone and hydrocortisone $n=1$.

Suppressed 170HP concentrations were frequent and $58 \%(15 / 26)$ of the patients had at least one value below or at the level of detection $(\leq 5 \mathrm{nmol} / \mathrm{l})$. However, the $24 \mathrm{~h}$ median $17 \mathrm{OHP}$ value was very high $(\geq 96 \mathrm{nmol} / \mathrm{l})$ in $19 \%(5 / 26)$. Urinary pregnanetriol was in the reference range $(<6 \mu \mathrm{mol} / 24 \mathrm{~h})$ in $39 \%(11 / 28)$ and very high $(\geq 110 \mu \mathrm{mol} / 24 \mathrm{~h})$ in $14 \%(4 / 28)$. The majority $(n=26 ; 87 \%)$ received fludrocortisone, mean dose $0.11 \pm 0.06 \mathrm{mg}$, with similar doses in the different groups. Most renin levels were normal. Testosterone levels were decreased in older compared to younger patients but also compared to controls (Table 1). SHBG was similar in all the groups (not shown).

Cardiovascular disease and/or cardiovascular preventive medications were revealed in two patients and two controls. One 67-year-old patient (I172N) had dyslipidemia, coronary atherosclerosis, and hypertension. One 56-year-old patient (I172N) was treated for dyslipidemia. One 67-year-old control had been operated on for an abdominal aortic aneurysm and

Table 1 Blood pressure, anthropometry, body composition (by dual-energy X-ray absorptiometry), and hormones in adult males with congenital adrenal hyperplasia due to 21-hydroxylase deficiency younger than 30 and at least 30 years of age and age-matched male controls (mean \pm S.D. or median and range).

\begin{tabular}{|c|c|c|c|c|c|c|}
\hline & $\begin{array}{c}\text { Patients } \\
(<30 \text { years })\end{array}$ & $\begin{array}{l}\text { Controls } \\
(<30 \text { years })\end{array}$ & $P$ value & $\begin{array}{c}\text { Patients } \\
(\geq 30 \text { years })\end{array}$ & $\begin{array}{c}\text { Controls } \\
(\geq 30 \text { years })\end{array}$ & $P$ value \\
\hline Height (cm) & $169.0 \pm 10.9$ & $180.3 \pm 8.0$ & 0.006 & $168.3 \pm 8.7$ & $181.6 \pm 6.5$ & $<0.001$ \\
\hline BMI $\left(\mathrm{kg} / \mathrm{m}^{2}\right)$ & $22.6 \pm 2.9$ & $22.3 \pm 4.2$ & NS & $28.1 \pm 4.5^{*}$ & $25.6 \pm 2.6^{\ddagger}$ & 0.031 \\
\hline Waist/hip ratio & $0.84 \pm 0.05$ & $0.86 \pm 0.06$ & NS & $0.95 \pm 0.05^{*}$ & $0.91 \pm 0.06^{\S}$ & 0.022 \\
\hline $\mathrm{T}$ fat mass $\left(\mathrm{kg} / \mathrm{m}^{2}\right)$ & $4.39 \pm 2.38$ & $4.75 \pm 3.04$ & NS & $8.22 \pm 3.17^{\star}$ & $5.85 \pm 2.71$ & 0.012 \\
\hline Trunk fat mass $\left(\mathrm{kg} / \mathrm{m}^{2}\right)$ & $2.36 \pm 1.61$ & $2.29 \pm 1.53$ & NS & $5.07 \pm 2.15^{\star}$ & $3.59 \pm 1.75$ & 0.017 \\
\hline Trunk/T fat mass & $0.50 \pm 0.07$ & $0.56 \pm 0.04$ & 0.055 & $0.58 \pm 0.06$ & $0.58 \pm 0.05$ & NS \\
\hline $\mathrm{T}$ lean mass $\left(\mathrm{kg} / \mathrm{m}^{2}\right)$ & $17.8 \pm 2.8$ & $17.2 \pm 1.6$ & NS & $18.8 \pm 2.3$ & $18.6 \pm 1.1^{\ddagger}$ & NS \\
\hline $\mathrm{T}$ fat $/ \mathrm{T}$ lean mass & $0.24 \pm 0.14$ & $0.27 \pm 0.15$ & NS & $0.44 \pm 0.16^{\ddagger}$ & $0.32 \pm 0.15$ & 0.016 \\
\hline Leg lean mass $\left(\mathrm{kg} / \mathrm{m}^{2}\right)$ & $5.54 \pm 0.59$ & $6.02 \pm 0.62$ & NS & $6.04 \pm 0.71$ & $6.33 \pm 0.42$ & 0.096 \\
\hline S-testo $(\mathrm{nmol} / \mathrm{l})$ & $16.8 \pm 3.9$ & $18.7 \pm 5.0$ & NS & $13.1 \pm 5.1^{\ddagger}$ & $16.2 \pm 4.8$ & 0.045 \\
\hline P-renin (ng/l) & $27.7 \pm 18.7$ & $20.6 \pm 15.2$ & NS & $22.5(8.6-303)$ & $8.7(2.0-25)$ & $<0.001$ \\
\hline $24 \mathrm{~h} \mathrm{SBP}(\mathrm{mmHg})$ & $130 \pm 12$ & $120 \pm 10$ & NS & $129 \pm 12$ & $125 \pm 9$ & NS \\
\hline $24 \mathrm{~h}$ DBP $(\mathrm{mmHg})$ & $74 \pm 4$ & $70 \pm 4$ & 0.081 & $77 \pm 7$ & $75 \pm 7$ & NS \\
\hline Night SBP $(\mathrm{mmHg})$ & $118+5$ & $113+14$ & NS & $117+11$ & $117+9$ & NS \\
\hline Night DBP $(\mathrm{mmHg})$ & $66 \pm 7$ & $61 \pm 7$ & NS & $69 \pm 7$ & $67 \pm 6$ & NS \\
\hline
\end{tabular}

${ }^{\star} P<0.001,{ }^{\dagger} P<0.01,{ }^{\ddagger} P<0.05,{ }^{\S} P=0.05-0.099$ compared to younger counterparts (patients or controls respectively). SBP, systolic blood pressure; DBP, diastolic blood pressure; 24 h, 24 h ambulatory measurements; NS, not significant; night, all values were measured at 2300-0600 h; BMI, body mass index; T, total; S-testo, serum testosterone. 
had recovered from stroke. One 61-year-old control was treated for hypertension.

No past or present differences in smoking habits were found between $\mathrm{CAH}$ males and controls (current and past smokers 23 vs $25 \%, P=N S$ ) or in the different subgroups (not shown).

\section{Adrenomedullary function}

Urinary epinephrine secretion was reduced in the $\mathrm{CAH}$ group compared to controls due to low levels in the null and I2splice groups, whereas concentrations in the milder I172N genotype were similar to those in controls and higher than in the null group (Fig. 1). A tendency to increased excretion of norepinephrine in the I172N group was found. Concentrations were similar in older and younger patients (not shown).

\section{Body composition}

Patients were shorter than controls (Table 1). Obesity (BMI $>30 \mathrm{~kg} / \mathrm{m}^{2}$ ) was found in $23 \%$ (7/30) of patients
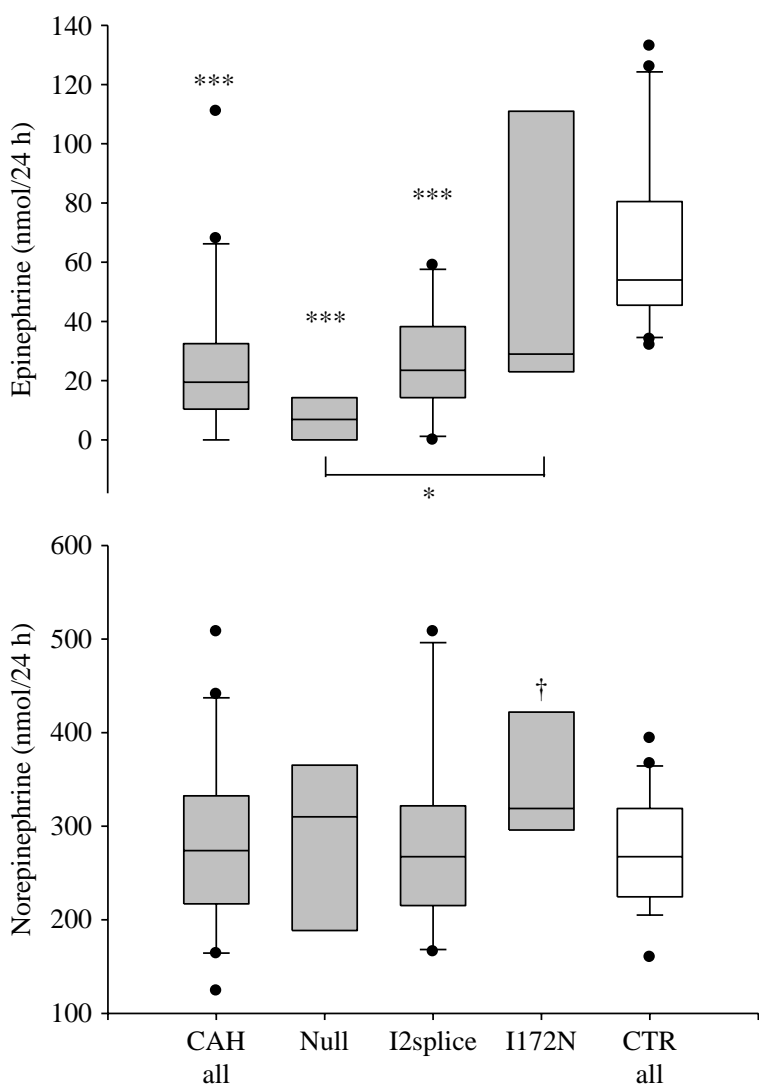

Figure 1 Urinary catecholamines in adult males with congenital adrenal hyperplasia and in the three most common CYP21A2 (Null, I2splice, and I172N) and age- and sex-matched controls. Box plot demonstrates the 10th, 25th, 50th, 75th, and 90th percentiles. All $P$ values compared to controls if not indicated otherwise. $P$ value: ${ }^{*}<0.05,{ }^{* *}<0.01,{ }^{* * *}<0.001,{ }^{\dagger} 0.057$. and $9 \%(3 / 32)$ of controls $(P=N S)$. Indices of body composition were similar to controls in younger patients, whereas older patients had a higher BMI, waist/hip ratio, total and truncal fat, and fat/lean ratio than both agematched controls and younger patients. Older controls had a higher BMI and a tendency to a higher waist/hip ratio than younger controls (Table 1 ). Older patients showed a tendency to decreased leg lean mass.

\section{Metabolic evaluation}

Markers of glucose control None had diabetes, impaired glucose tolerance, or acanthosis nigricans. All investigated parameters were similar in younger patients and controls, while older patients had lower fasting P-glucose. HbA1c tended to be higher in older than in younger patients (Table 2). During OGTT, the area under the curve (AUC) for insulin was increased in all patients compared to controls (3741 (750-8295) vs 2108 (1440-12 267) $\mathrm{mU} / \mathrm{l} \times \min , P=0.033)$. The $2 \mathrm{~h}$ insulin level was higher in older patients than in controls.

Liver enzymes GGT values were elevated in all CAH males compared to controls (0.36 (0.10-2.10) vs 0.20 (0.10-1.40) $\mu \mathrm{kat} / \mathrm{l}, P=0.020)$, as well as in older patients compared to controls and to younger patients. GGT was correlated with total and truncal fat mass $(r=0.521, P=0.003 ; r=0.488, P=0.006)$. ALT and ALP concentrations were similar in all CAH groups and controls (not shown). No difference in alcohol intake, defined as standard drinks/week, was found between the different groups (not shown).

Serum lipids No differences were found between $\mathrm{CAH}$ and control males. The HDL/LDL ratio was lower and LDL and triglycerides were higher in older patients than in younger ones. Older controls showed higher total cholesterol and LDL values and a tendency to raised triglycerides compared to their younger counterparts (Table 2). The results did not differ when the two patients on statin medication were excluded.

Other cardiovascular risk markers Lp(a) was similar in the different age groups. Homocysteine was decreased in younger patients compared to controls and older patients. Urinary albumin tended to be increased in older patients compared to controls (Table 2).

\section{Heart rate and blood pressure}

The average $24 \mathrm{~h}$ heart rate was increased up to $20 \%$ in the entire $\mathrm{CAH}$ cohort and the older $\mathrm{CAH}$ males compared to controls (Fig. 2). Tendencies to higher heart rates in older patients than in younger ones and the opposite among controls were demonstrated. In patients heart rate was negatively correlated with testosterone $(r=-0.605, P=0.003)$, positively with 
Table 2 Metabolic and cardiovascular evaluations in adult males with congenital adrenal hyperplasia due to 21 -hydroxylase deficiency younger than 30 and at least 30 years of age and age-matched male controls (mean \pm s.D. or median and range).

\begin{tabular}{|c|c|c|c|c|c|c|}
\hline & $\begin{array}{c}\text { Patients } \\
(<30 \text { years })\end{array}$ & $\begin{array}{l}\text { Controls } \\
(<30 \text { years })\end{array}$ & $P$ value & $\begin{array}{c}\text { Patients } \\
\text { ( } \geq 30 \text { years) }\end{array}$ & $\begin{array}{c}\text { Controls } \\
\text { ( } \geq 30 \text { years) }\end{array}$ & $P$ value \\
\hline B-HbA1c (\%) & $4.0 \pm 0.4$ & $4.3 \pm 0.5$ & NS & $4.3 \pm 0.3^{\S}$ & $4.3 \pm 0.3$ & NS \\
\hline P-glucose $(\mathrm{mmol} / \mathrm{l})$ & $4.2 \pm 0.3$ & $4.3 \pm 0.7$ & NS & $4.2 \pm 0.4$ & $4.5 \pm 0.4$ & 0.049 \\
\hline P-glucose $(\mathrm{mmol} / / \mathrm{min})^{\mathrm{a}}$ & $637 \pm 97$ & $626 \pm 47$ & NS & $738 \pm 135^{\S}$ & $627 \pm 136$ & 0.081 \\
\hline S-insulin $0 \min (\mathrm{mU} / \mathrm{l})$ & $5.7(2.3-23)$ & $6.9(3.9-19)$ & NS & $7.1(0.5-67)$ & $6.1(1.4-34)$ & NS \\
\hline S-insulin 120 min (mÚ/l) & $23.0(4.3-92)$ & $30.4(3.2-50)$ & NS & $32.0(2.9-460)$ & $15.6(2.1-143)^{\S}$ & 0.045 \\
\hline S-insulin $(\mathrm{mU} / / \mathrm{min})^{\mathrm{a}}$ & $4278 \pm 3755$ & $2345 \pm 1425$ & NS & $6101 \pm 3716$ & $3005 \pm 2506$ & 0.097 \\
\hline S-GGT ( $\mu \mathrm{kat} / \mathrm{l})$ & $0.25 \pm 0.09$ & $0.22 \pm 0.18$ & NS & $0.48(0.10-2.1)^{\dagger}$ & $0.21(0.10-1.4)$ & 0.038 \\
\hline S-TC $(\mathrm{mmol} / \mathrm{l})$ & $4.08 \pm 0.89$ & $3.99 \pm 0.66$ & NS & $4.63 \pm 0.96$ & $4.90 \pm 0.92^{\dagger^{\prime}}$ & NS \\
\hline S-HDL (mmol//l) & $1.47 \pm 0.39$ & $1.32 \pm 0.29$ & NS & $1.27 \pm 0.31$ & $1.39 \pm 0.36$ & NS \\
\hline S-LDL $(\mathrm{mmol} / \mathrm{l})$ & $2.22 \pm 0.86$ & $2.32 \pm 0.45$ & NS & $2.80 \pm 0.80^{\ddagger}$ & $2.95 \pm 0.88^{\ddagger}$ & NS \\
\hline HDL/LDL ratio & $0.77 \pm 0.37$ & $0.59 \pm 0.17$ & NS & $0.52 \pm 0.26^{\ddagger}$ & $0.53 \pm 0.24$ & NS \\
\hline S-TG (mmol/l) & $0.89 \pm 0.49$ & $0.90 \pm 0.41$ & NS & $1.49 \pm 0.97^{\ddagger}$ & $1.40 \pm 0.75^{\S}$ & NS \\
\hline S-Lp(a) $(\mathrm{mg} / \mathrm{l})$ & $220(30-1030)$ & $133(50-1386)$ & NS & $157(2 \overline{0}-1637)$ & $207(50-1858)$ & NS \\
\hline P-homocyst $(\mu \mathrm{mol} / \mathrm{l})$ & $9.0 \pm 2.1$ & $13.2 \pm 3.9$ & 0.011 & $11.0(6.6-24)^{f}$ & $12.0(6.7-21)$ & NS \\
\hline U-albumin (mg/l) & $8(2-19)$ & $5.5(2-232)$ & NS & $6.6(2-74)$ & $5(2-26)$ & 0.075 \\
\hline
\end{tabular}

${ }^{\star} P<0.001,{ }^{\dagger} P<0.01,{ }^{\ddagger} P<0.05,{ }^{\S} P=0.05-0.099$ compared to younger counterparts (patients or controls respectively). B, blood; $\mathrm{S}$, serum; $\mathrm{P}$, plasma; $U$, urinary; GGT, $\gamma$-glutamyl transpeptidase; TC, total cholesterol; TG, triglyceride; Lp(a), lipoprotein-(a); homocyst, homocysteine; NS, not significant.

${ }^{a}$ Area under curve $0-120 \mathrm{~min}$ in oral glucose tolerance test.

total and truncal fat mass $(r=0.579$ and 0.597 , $P=0.005$ and 0.003$)$, night $24 \mathrm{~h}$ diastolic blood pressure $(r=0.458, \quad P=0.042)$, homocysteine $(r=0.430, P=0.046)$, and positive tendency with HbAlc $(r=0.417, P=0.060)$ and urinary norepinephrine $(r=0.438, \quad P=0.079)$. In multiple regression, the highest correlation with heart rate was with testosterone and HbA1c $(r=0.721, P=0.001)$.

Twenty-four hours ambulatory blood pressure revealed no differences between all $\mathrm{CAH}$ males and controls, either regarding average $24 \mathrm{~h}$ blood pressure or day or night periods (not shown). There was a tendency of slightly higher mean diastolic blood pressures in younger patients, otherwise all pressures were similar in older and younger patients compared with controls (Table 1). The results did not differ when the patient and the two controls on antihypertensive medication were excluded.

\section{BMI $<25 \mathrm{~kg} / \mathrm{m}^{2}$}

If only subjects with BMI $<25 \mathrm{~kg} / \mathrm{m}^{2}$ were compared (14 CAH males versus 17 controls), the only differences that persisted were shorter height $(P<0.001)$ and lower epinephrine $(P=0.002)$, however, tendencies were found in GGT $(0.29(0.10-0.78)$ vs $0.12(0.10-0.97)$ $\mu \mathrm{kat} / \mathrm{l}, P=0.071)$ and $\mathrm{HbA} 1 \mathrm{c}(4.1 \pm 0.3$ vs $4.4 \pm 0.4 \%$, $P=0.068$ ).

\section{Characteristics of the three most common genotypes}

Indications for increased cardiovascular and metabolic risk were predominantly found in the $1172 \mathrm{~N}$ group. Compared with controls, they had significantly higher waist/hip ratios and GGT and tended to have higher BMI and total fat mass (Table 3). Total lean mass was elevated. Insulin AUC after an oral glucose load was higher than in controls and in the other genotypes. Heart rate was increased (Fig. 1). The mean systolic and night diastolic blood pressure were higher compared with controls, the latter also tended to be elevated compared to the other genotypes. However, there was a tendency to lower homocysteine. Patients in the null group had significantly reduced leg lean mass and fasting insulin levels and a tendency to elevated $\operatorname{Lp}(\mathrm{a})$. In the I2splice group, heart rate was increased and urinary albumin tended to be elevated (Table 3 ).

\section{Characteristics of groups on different glucocorticoids}

Increased cardiovascular and metabolic risk were mainly seen in patients on short-acting glucocorticoids (Table 4) in spite of similar doses of hydrocortisone equivalents (hydrocortisone/cortisone acetate versus prednisolone: $19.9 \pm 6.3$ vs $16.8 \pm 4.6 \mathrm{mg} / \mathrm{m}^{2}, P=\mathrm{NS}$ ). However, GGT was slightly higher in the prednisolone group compared with controls.

\section{Discussion}

We studied cardiovascular and metabolic risk profiles in a cohort of $\mathrm{CAH}$ males where the majority of the patients were $\geq 30$ years old. The prevalence of manifest cardiovascular disease, including hypertension and dyslipidemia, was low, as expected, since only 13\% were $>50$ years old. Nevertheless, there were some indications of increased cardiovascular and metabolic 

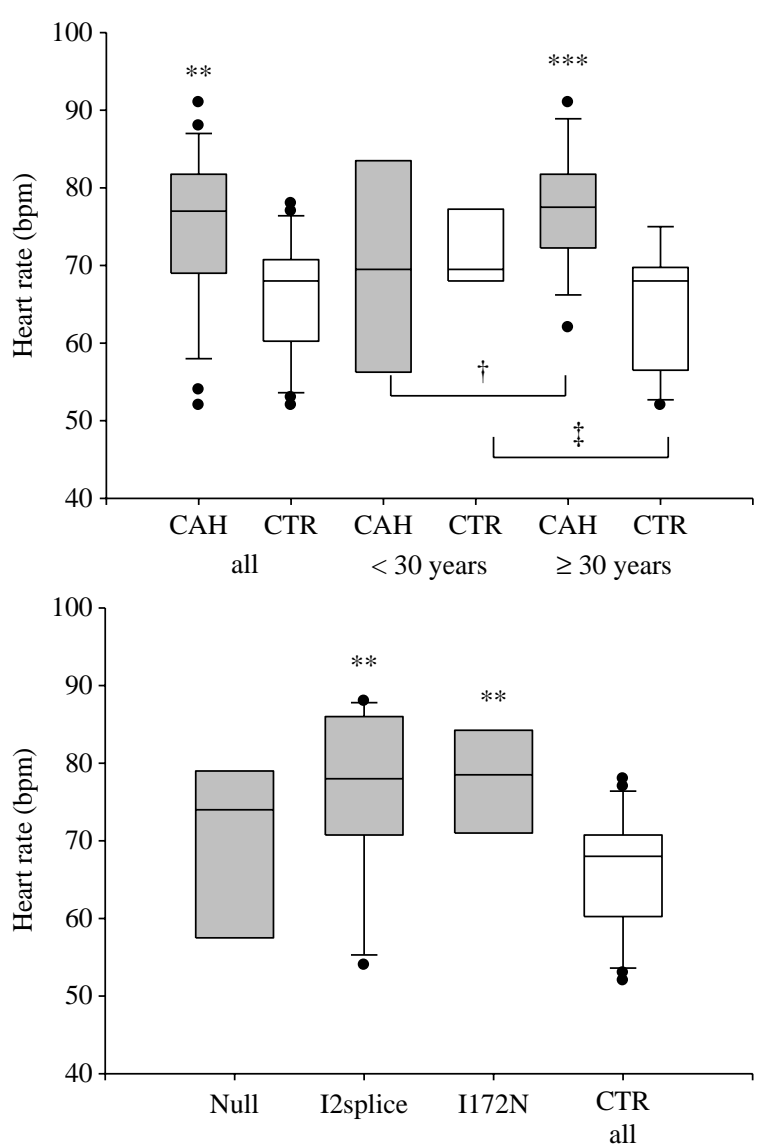

Figure 2 Heart rate measured with $24 \mathrm{~h}$ ambulatory monitor in adult males with congenital adrenal hyperplasia, divided into younger than 30 years or older (upper panel), and into the three most common CYP21A2 genotype groups, (Null, I2splice, and I172N) (lower panel) and age- and sex-matched controls. Box plot demonstrates the 10th, 25th, 50th, 75th, and 90th percentiles. All $P$ values compared to controls if not indicated otherwise. $P$ value: ${ }^{*}<0.05,{ }^{\star *}<0.01,{ }^{* \star *}<0.001,{ }^{\dagger} 0.091,{ }^{\ddagger} 0.062$.

risk in CAH males $\geq 30$ years old. They had higher body fat, serum GGT, insulin responses to glucose administration and heart rates, and lower testosterone levels compared to age-matched controls. In the younger group, none of these parameters differed significantly from controls. With respect to genotypes, indications for increased risk were mainly found in patients with the less severe $1172 \mathrm{~N}$ mutation. If only those with a healthy BMI (i.e. $<25 \mathrm{~kg} / \mathrm{m}^{2}$ ) were compared, most differences in cardiovascular risk between $\mathrm{CAH}$ males and controls disappeared.

Many studies have demonstrated elevated BMI $(9,15$, $16,20,23)$ in adults with CAH. Measurement of body composition using DXA has previously demonstrated increased fat mass in young adults with CAH $(15,16)$. Interestingly, two other studies found increased fat mass in male, but not in female, CAH patients $(14,17)$. We found increased fat mass only in the older males consistent with the latter studies. In contrast, we have previously reported increased lean mass in CAH females $\geq 30$ years old as an explanation for elevated BMI (20). The reason for these gender differences are unknown but could be attributed to differences in lifestyle and physical activity.

Although no study has demonstrated increased frequency of T2DM in CAH, an increase in gestational diabetes, a strong predictor of future T2DM, has been reported $(5,20)$. Our patients had increased insulin release during the OGTT and older patients tended to have higher HbAlc than younger ones, suggesting an increased risk of T2DM in the older CAH males. Insulin resistance has been found in adult $\mathrm{CAH}$ by all investigators $(6,8,9,12,13,18,20-23)$, but one (18) and has most commonly been expressed as homeostasis model assessment (HOMA) index. We did not calculate this index because fasting glucose was low in our patients, which may lead to a falsely low estimation of insulin resistance.

GGT has been demonstrated to be independently associated with cardiovascular mortality in a doseresponse relationship even in the normal range (26). We found elevated GGT in the older male patients and there was a positive association between GGT and body fat. This small increment is probably only of a minor clinical impact and has previously also been found elevated in CAH women $\geq 30$ years old (6).

Most studies of lipids in CAH have shown normal values $(9,18,20)$. We found similar lipid levels in patients and controls, but an unfavorable HDL/LDL ratio in older male patients compared with younger ones. Homocysteine, another marker of increased cardiovascular risk, has been analyzed in one NC-CAH study and found to be similar to that in controls (18). In contrast, our younger $\mathrm{CAH}$ males had decreased homocysteine, which may give cardiovascular protection.

Increased heart rate is a known risk factor for cardiovascular and noncardiovascular death, especially in men, with some studies finding heart rate being independent of other cardiovascular risk factors $(27$, 28). Even a small increment of a few beats per minute within the normal range can increase the cardiovascular risk (28). Our younger patients had normal heart rates in accord with previous studies of young patients (29-31). The heart rate in CAH males was correlated with other cardiovascular risk factors. Decreased testosterone levels and the extent of glycemic control explained around $50 \%$ of the elevated heart rate.

Single blood pressure measurements in adult $\mathrm{CAH}$, mainly in females, have found values similar to controls $(20,21)$ or elevated (23). No differences from controls were found by us in $24 \mathrm{~h}$ ambulatory measurements with the exception of one genotype group (see below). On the other hand, $24 \mathrm{~h}$ ambulatory measurements in children and adolescents have demonstrated elevated day and night time systolic pressures, however, they were more obese than controls (32). 
Table 3 Body composition and other cardiovascular and metabolic risk variables in adult male patients representing the three most common CYP21A2 genotype groups and male controls (mean \pm s.D. or median and range). Only variables that differ between patients and controls or between genotypes are shown.

\begin{tabular}{|c|c|c|c|c|c|c|c|}
\hline & Null $(n=7)$ & $\begin{array}{l}P \text { versus } \\
\text { controls }\end{array}$ & $\begin{array}{c}\text { I2splice } \\
(n=11)\end{array}$ & $\begin{array}{l}P \text { versus } \\
\text { controls }\end{array}$ & $\begin{array}{l}\mathbf{I 1 7 2 N} \\
(n=9)\end{array}$ & $\begin{array}{l}P \text { versus } \\
\text { control }\end{array}$ & $\begin{array}{c}\text { Controls } \\
(n=32)\end{array}$ \\
\hline Age (years) & $34.5 \pm 9.5$ & NS & $31.6 \pm 9.4$ & NS & $41.0 \pm 14.9$ & NS & $36.5 \pm 11.9$ \\
\hline BMI $\left(\mathrm{kg} / \mathrm{m}^{2}\right)$ & $25.9 \pm 3.8$ & NS & $25.1 \pm 5.0$ & NS & $28.5 \pm 5.2$ & 0.071 & $24.53 \pm 3.57$ \\
\hline Waist/hip ratio & $0.93 \pm 0.07$ & NS & $0.89 \pm 0.09$ & NS & $0.95 \pm 0.07$ & 0.038 & $0.89 \pm 0.01$ \\
\hline $\mathrm{T}$ fat mass $\left(\mathrm{kg} / \mathrm{m}^{2}\right)$ & $6.97 \pm 4.10$ & NS & $6.38 \pm 3.53$ & NS & $7.78 \pm 3.46$ & 0.055 & $5.56 \pm 2.79$ \\
\hline Trunk/T fat mass & $0.57 \pm 0.06$ & NS & $0.54 \pm 0.06$ & 0.038 & $0.55 \pm 0.09$ & NS & $0.58 \pm 0.05$ \\
\hline T lean mass $\left(\mathrm{kg} / \mathrm{m}^{2}\right)$ & $18.0+1.2$ & NS & $17.7+2.3$ & NS & $20.2+2.8^{\ddagger, \|}$ & 0.005 & $18.2+1.4$ \\
\hline Leg lean mass $\left(\mathrm{kg} / \mathrm{m}^{2}\right)$ & $5.73 \pm 0.60$ & 0.019 & $5.88 \pm 0.72$ & 0.065 & $6.07 \pm 0.76$ & NS & $6.25 \pm 0.49$ \\
\hline $24 \mathrm{~h}$ SBP $(\mathrm{mmHg})$ & $128 \pm 16$ & NS & $125 \pm 8$ & NS & $134 \pm 13$ & 0.044 & $124 \pm 9$ \\
\hline Night DBP (mmHg) & $63 \pm 8$ & NS & $69 \pm 6$ & NS & $73 \pm 5^{\S}$ & 0.042 & $66 \pm 7$ \\
\hline S-insulin $0 \mathrm{~min}(\mathrm{mE} / \mathrm{l})$ & $4.2(0.5-6.4)$ & 0.028 & $8.5(4.1-23)$ & NS & $8.9(2.3-11)^{\S}$ & NS & $6.5(1.4-33)$ \\
\hline S-insulin $(\mathrm{mU} / \mathrm{min})^{\mathrm{a}}$ & $3030 \pm 822$ & NS & $5114 \pm 4052$ & NS & $8491 \pm 3427^{\dagger, \pi}$ & 0.005 & $2884 \pm 2401$ \\
\hline S-GGT $(\mu \mathrm{kat} / \mathrm{l})$ & $0.27(0.10-0.53)$ & NS & $0.40(0.10-0.89)$ & NS & $0.40(0.17-2.1)$ & 0.026 & $0.20(0.10-1.4)$ \\
\hline S-Lp(a) $(\mathrm{mg} / \mathrm{l})$ & $585(120-1637)$ & 0.065 & $110(20-920)$ & NS & $157(40-1092)^{\S}$ & NS & $180(50-1858)$ \\
\hline P-homocyst $(\mu \mathrm{mol} / \mathrm{l})$ & $10.0(6.0-24)$ & NS & $12.0(6.9-20)$ & NS & $11.0(6.6-12)$ & 0.063 & $12.0(6.7-22)$ \\
\hline U-albumin (mg/l) & $8(3-19)$ & NS & $10(2-74)$ & 0.061 & $5.4(2.4-49)$ & NS & $5(2-232)$ \\
\hline
\end{tabular}

${ }^{\star} P<0.001,{ }^{\dagger} P<0.01,{ }^{\ddagger} P<0.05,{ }^{\S} P=0.05-0.099$ compared to other genotypes. BMI, body mass index; $\mathrm{T}$, total, B, blood; $\mathrm{S}$, serum; $\mathrm{P}$, plasma; $\mathrm{U}$, urinary; GGT, $\gamma$-glutamyl transpeptidase; TC, total cholesterol; TG, triglyceride; Lp(a), lipoprotein-(a); homocyst, homocysteine; NS, not significant; SBP, systolic blood pressure; DBP, diastolic blood pressure; $24 \mathrm{~h}, 24 \mathrm{~h}$ ambulatory measurements; night, all values were measured at $2300-0600 \mathrm{~h}$. " Post hoc null versus I172N, $P=0.072$ and 12 splice versus $1172 \mathrm{~N}, P=0.038$. "Post hoc null versus $1172 \mathrm{~N}, P=0.018$.

${ }^{a}$ Area under curve $0-120 \mathrm{~min}$ in oral glucose tolerance test.

Both in the present cohort and in our previous report on $\mathrm{CAH}$ females (20), we found that the younger patients apart from a shorter height were similar to controls with respect to body composition and metabolic and cardiovascular risk markers whereas the older patients had more unfavorble profiles (20). These differences still persisted even if the division between younger and older males was set at 35 years of age to make the groups more even (data not shown). The reason is not known, but it can be speculated whether the higher lifetime glucocorticoid exposure may be of importance. To explore that further more individuals above the age of 50 years should be evaluated. The management of therapy in the two groups may also differ. The majority of the older patients were treated in general pediatric care during childhood, but the younger ones have been treated within or with backup from pediatric endocrinology units, most likely with a more optimal corticosteroid therapy and access to lifestyle interventions. With national neonatal screening introduced in Sweden 1986 (33), all patients with classic $\mathrm{CAH}$ can be identified during the first weeks of life and be adequately treated onward. Therefore, outcome will hopefully improve gradually.

In children, the preferred glucocorticoid is hydrocortisone due to less growth-suppressive effects (1), while in adults longer acting preparations such as prednisolone is often used $(20,23)$. Interestingly, more cardiovascular and metabolic risk factors were found in those treated with short-acting glucocorticoids

Table 4 Body composition and other cardiovascular and metabolic risk variables in adult male patients on different glucocorticoids and male controls (mean \pm s.D. or median and range). Only variables that differ between patients and controls or between the glucocorticoids are shown.

\begin{tabular}{lccccc}
\hline & $\begin{array}{c}\text { Prednisolone } \\
(n=18)\end{array}$ & $\begin{array}{c}\boldsymbol{P} \text { versus } \\
\text { controls }\end{array}$ & $\begin{array}{c}\text { HC or CoAc } \\
(n=8)\end{array}$ & $\begin{array}{c}\boldsymbol{P} \text { versus } \\
\text { controls }\end{array}$ & $\begin{array}{c}\text { Controls } \\
(n=32)\end{array}$ \\
\hline BMI $\left(\mathrm{kg} / \mathrm{m}^{2}\right)$ & $25.5 \pm 4.6$ & $\mathrm{NS}$ & $29.0 \pm 4.9^{\dagger}$ & 0.006 & $24.5 \pm 3.6$ \\
Waist/hip ratio & $0.89 \pm 0.07$ & $\mathrm{NS}$ & $0.97 \pm 0.06^{*}$ & 0.005 & $0.89 \pm 0.01$ \\
T fat mass $\left(\mathrm{kg} / \mathrm{m}^{2}\right)$ & $6.57 \pm 3.49$ & $\mathrm{NS}$ & $8.35 \pm 3.62$ & 0.024 & $5.56 \pm 2.79$ \\
Trunk fat mass $\left(\mathrm{kg} / \mathrm{m}^{2}\right)$ & $3.84 \pm 2.14$ & $\mathrm{NS}$ & $5.39 \pm 2.73$ & 0.013 & $3.35 \pm 1.79$ \\
24 h Heart rate (BPM) & $74.4 \pm 10.7$ & 0.012 & $72.7 \pm 9.5$ & 0.044 & $66.4 \pm 7.6$ \\
S-testo $(\mathrm{nmol} / \mathrm{l})$ & $15.3 \pm 5.5$ & $\mathrm{NS}$ & $12.3 \pm 5.6$ & 0.024 & $17.0 \pm 4.4$ \\
S-insulin 0 min $(\mathrm{mE} / \mathrm{l})$ & $5.0(0.5-11)$ & $\mathrm{NS}$ & $11.0(3.9-15)$ & 0.052 & $6.5(1.4-33)$ \\
S-insulin $(\mathrm{mU} / \mathrm{l} \mathrm{min})^{\mathrm{a}}$ & $4124 \pm 2470$ & $\mathrm{NS}$ & $7098 \pm 4561$ & 0.044 & $2884 \pm 2401$ \\
S-GGT $(\mu \mathrm{kat} / \mathrm{l})$ & $0.40(0.1-1.6)$ & 0.021 & $0.30(0.15-2.1)$ & $\mathrm{NS}$ & $0.20(0.10-1.4)$ \\
S-LDL $(\mathrm{mmol} / \mathrm{l})$ & $2.97 \pm 0.74$ & $\mathrm{NS}$ & $2.23 \pm 0.75^{\dagger}$ & $\mathrm{NS}$ & $2.75 \pm 0.82$ \\
P-homocyst $(\mu \mathrm{mol} / \mathrm{l})$ & $11.5(6.0-24)$ & $\mathrm{NS}$ & $10.0(6.9-14)$ & 0.056 & $12.0(6.7-22)$ \\
\hline
\end{tabular}

${ }^{\star} P<0.05,{ }^{\dagger} P=0.05-0.099$ compared to the glucocorticoid group. $\mathrm{HC}$, hydrocortisone; CoAC, cortisone acetate; BPM, beats per min, S-testo, serum testosterone; NS, not significant. GGT, $\gamma$-glutamyl transpeptidase; homocyst, homocysteine.

${ }^{a}$ Area under curve $0-120 \mathrm{~min}$ in oral glucose tolerance test. 
compared with prednisolone maybe due to better compliance and control of androgens. Comparing different glucocorticoids in $\mathrm{CAH}$ merits further studies.

Comparisons between the three most common genotypes revealed that the $1172 \mathrm{~N}$ group was the one most negatively affected having indices of increased fat mass, glucose-stimulated insulin release, and GGT as well as higher systolic and diastolic blood pressures. The mean glucocorticoid and mineralocorticoid doses were the same as in the null and I2splice groups. Possibly, the explanation for a more unfavorable profile is that the doses of corticosteroids were too high considering the milder disease. Although the sample was small and some differences were only tendencies, these results can alert us to consider genotype in monitoring corticosteroid dosing in classic CAH.

Moreover, none of the $I 172 \mathrm{~N}$ patients had been screened with $17 \mathrm{OHP}$ at birth and it can be speculated whether a late diagnosis with prolonged postnatal androgen excess could lead to adverse metabolic effects. In a recent study, NC-CAH boys and girls had more parameters of insulin resistance and higher systolic blood pressure compared with controls, in contrast to classic $\mathrm{CAH}$ boys and girls diagnosed on average 5 years earlier (34).

Adrenomedullary function was studied in the present cohort. Epinephrine production has been shown to be impaired in adolescents and young adults with classic CAH (1, 29-31). This defect is certainly the result of insufficient prenatal cortisol secretion from the adrenal cortex, necessary for adrenomedullary organogenesis and epinephrine production (1). We could demonstrate for the first time in an older cohort that only patients with classic $\mathrm{CAH}$ having severe mutations had reduced epinephrine production (null and I2splice), whereas those carrying the milder $1172 \mathrm{~N}$ had normal production. Whether differences in epinephrine secretion can influence cardiovascular risk profiles have yet to be explored.

The main limitation of this study is its limited size. This primarily affects the power of the study making differences found difficult to reach statistically significant levels. Another limitation is assessing the impact of steroid treatment. Neither type of steroid used nor their cumulative lifetime dose were available and we used the dose of the present steroid in the calculations. Steroid excess at an early age may certainly have a continuing negative metabolic impact in adult age. For example, Knorr et al. (35) found that overtreatment during infancy increased the risk of obesity later despite adequate treatment for several years thereafter (35).

\section{Conclusion}

Indications of an increased cardiovascular risk in $\mathrm{CAH}$ males were mainly found in those $\geq 30$ years old and in the I172N genotype group. On the other hand, younger
CAH males did not differ from age-matched controls. This is likely to reflect a better management in recent years and the neonatal screening program may lead to further improvements.

\section{Declaration of interest}

The authors declare that there is no conflict of interest that could be perceived as prejudicing the impartiality of the research reported.

\section{Funding}

This work was supported by the Magn. Bergvalls Foundation, Karolinska Institutet, Stockholm County Council, and Göteborg Medical Society.

\section{Acknowledgements}

We thank R N Anette Härström and R N Ingrid Hansson, for their excellent care of patients and controls. We also thank Prof. Martin E Ritzén for valuable advice.

\section{References}

1 Merke DP \& Bornstein SR. Congenital adrenal hyperplasia. Lancet 2005365 2125-2136. (doi:10.1016/S0140-6736(05)66736-0)

2 Wedell A, Thilén A, Ritzén EM, Stengler B \& Luthman H. Mutational spectrum of the steroid 21-hydroxylase gene in Sweden: implications for genetic diagnosis and association with disease manifestation. Journal of Clinical Endocrinology and Metabolism 199478 1145-1152. (doi:10.1210/jc.78.5.1145)

3 Falhammar H, Filipsson H, Holmdahl G, Janson PO, Nordenskjöld A, Hagenfeldt K \& Thorén M. Fractures and bone mineral density in adult women with 21-hydroxylase deficiency. Journal of Clinical Endocrinology and Metabolism $2007 \mathbf{9 2}$ 4643-4649. (doi:10.1210/jc.2007-0744)

4 Nordenskjöld A, Holmdahl G, Frisén L, Falhammar H, Filipsson H, Thorén M, Janson PO \& Hagenfeldt K. Type of mutation and surgical procedure affect long-term quality of life for women with congenital adrenal hyperplasia. Journal of Clinical Endocrinology and Metabolism 200893 380-386. (doi:10.1210/jc.2007-0556)

5 Hagenfeldt K, Janson PO, Holmdahl G, Falhammar H, Filipsson H, Frisén L, Thorén M \& Nordenskjöld A. Fertility and pregnancy outcome in women with congenital adrenal hyperplasia due to 21-hydroxylase deficiency. Human Reproduction $2008 \mathbf{2 3}$ 1607-1613. (doi:10.1093/humrep/den118)

6 Falhammar H, Filipsson H, Holmdahl G, Janson PO, Nordenskjöld A, Hagenfeldt K \& Thorén M. Increased liver enzymes in adult women with congenital adrenal hyperplasia due to 21-hydroxylase deficiency. Endocrine Journal 200956 601-608. (doi:10.1507/endocrj.K08E-312)

7 Frisén L, Nordenström A, Falhammar H, Filipsson H, Holmdahl G, Janson PO, Thorén M, Hagenfeldt K, Möller A \& Nordenskjöld A. Gender role behavior, sexuality, and psychosocial adaptation in women with congenital adrenal hyperplasia due to CYP21A2 deficiency. Journal of Clinical Endocrinology and Metabolism 200994 3432-3439. (doi:10.1210/jc.2009-0636)

8 Saygili F, Oge A \& Yilmaz C. Hyperinsulinemia and insulin insensitivity in women with nonclassical congenital adrenal hyperplasia due to 21-hydroxylase deficiency: the relationship between serum leptin levels and chronic hyperinsulinemia. Hormone Research 200563 270-274. (doi:10.1159/000086363)

9 Bachelot A, Plu-Bureau G, Thibaud E, Laborde K, Pinto G, Samara D, Nihoul-Fékété C, Kuttenn F, Polak M \& Touraine P. 
Long-term outcome of patients with congenital adrenal hyperplasia due to 21-hydroxylase deficiency. Hormone Research 200767 268-276. (doi:10.1159/000098017)

10 Maggio M \& Basaria S. Welcoming low testosterone as a cardiovascular risk factor. International Journal of Impotence Research 200921 261-264. (doi:10.1038/ijir.2009.25)

11 Mooij CF, Kroese JM, Claahsen-van der Grinten HL, Tack CJ \& Hermus AR. Unfavorable trends in cardiovascular and metabolic risk in pediatric and adult patients with congenital adrenal hyperplasia? Clinical Endocrinology 201073 137-146. (doi:10. $1111 /$ j.1365-2265.2009.03690.x)

12 Speiser PW, Serrat J, New MI \& Gertner JM. Insulin insensitivity in adrenal hyperplasia due to nonclassical steroid 21-hydroxylase deficiency. Journal of Clinical Endocrinology and Metabolism 1992 75 1421-1424. (doi:10.1210/jc.75.6.1421)

13 Paula FJ, Gouveia LM, Paccola GM, Piccinato CE, Moreira AC \& Foss MC. Androgen-related effects on peripheral glucose metabolism in women with congenital adrenal hyperplasia. Hormone and Metabolic Research 199426 552-556. (doi:10.1055/s-20071001755)

14 Cameron FJ, Kaymakci B, Byrt EA, Ebeling PR, Warne GL \& Wark JD. Bone mineral density and body composition in congenital adrenal hyperplasia. Journal of Clinical Endocrinology and Metabolism $1995 \mathbf{8 0}$ 2238-2243. (doi:10.1210/jc.80.7. 2238)

15 Hagenfeldt K, Ritzen EM, Ringertz H, Helleday J \& Carlstrom K. Bone mass and body composition of adult women with congenital virilizing 21-hydroxylase deficiency after glucocortioid treatment since infancy. European Journal of Endocrinology 2000143 667-671. (doi:10.1530/eje.0.1430667)

16 Stikkelbroeck NM, Oyen WJ, van der Wilt GJ, Hermus AR \& Otten BJ. Normal bone mineral density and lean body mass, but increased fat mass, in young adult patients with congenital adrenal hyperplasia. Journal of Clinical Endocrinology and Metabolism 2003 88 1036-1042. (doi:10.1210/jc.2002-021074)

17 Christiansen P, Molgaard C \& Muller J. Normal bone mineral content in young adults with congenital adrenal hyperplasia due to 21-hydroxylase deficiency. Hormone Research 200461 133-136. (doi:10.1159/000075588)

18 Bayraktar F, Dereli D, Ozgen AG \& Yilmaz C. Plasma homocysteine levels in polycystic ovary syndrome and congenital adrenal hyperplasia. Endocrine Journal 200451 601-608. (doi:10.1507/ endocrj.51.601)

19 Hoepffner W, Herrmann A, Willgerodt H \& Keller E. Blood pressure in patients with congenital adrenal hyperplasia due to 21-hydroxylase deficiency. Journal of Pediatric Endocrinology and Metabolism 200619 705-711.

20 Falhammar H, Filipsson H, Holmdahl G, Janson PO, Nordenskjöld A, Hagenfeldt K \& Thorén M. Metabolic profile and body composition in adult women with congenital adrenal hyperplasia due to 21-hydroxylase deficiency. Journal of Clinical Endocrinology and Metabolism 200792 110-116. (doi:10.1210/ jc.2006-1350)

21 Sartorato P, Zulian E, Benedini S, Mariniello B, Schiavi F, Bilora F, Pozzan G, Greggio N, Pagnan A, Mantero F \& Scaroni C. Cardiovascular risk factors and ultrasound evaluation of intimamedia thickness at common carotids, carotid bulbs, and femoral and abdominal aorta arteries in patients with classic congenital adrenal hyperplasia due to 21-hydroxylase deficiency. Journal of Clinical Endocrinology and Metabolism 200792 1015-1018. (doi:10.1210/jc.2006-1711)

22 Kroese JM, Mooij CF, van der Graaf M, Hermus AR \& Tack CJ. Pioglitazone improves insulin resistance and decreases blood pressure in adult patients with congenital adrenal hyperplasia. European Journal of Endocrinology 2009161 887-894. (doi:10. 1530/EJE-09-0523)

23 Arlt W, Willis DS, Wild SH, Krone N, Doherty EJ, Hahner S, Han TS, Carroll PV, Conway GS, Rees DA, Stimson RH, Walker BR,
Connell JM, Ross RJ \& the United Kingdom Congenital Adrenal Hyperplasia Adult Study Executive (CaHASE). Health status of adults with congenital adrenal hyperplasia: a cohort study of 203 patients. Journal of Clinical Endocrinology and Metabolism, 2010. (doi:10.1210/jc.2010-0917)

24 Liddle GW. Clinical pharmacology of anti-inflammatory steroids. Clinical Pharmacology and Therapeutics 19612 615-635.

25 Friedewald WT, Levy RI \& Fredrickson DS. Estimation of concentration of low density lipoprotein cholesterol in plasma without the use of the preparative ultracentrifuge. Clinical Chemistry $1972 \mathbf{1 8} 499-502$.

26 Ruttmann E, Brant LJ, Concin H, Diem G, Rapp K, Ulmer H \& Vorarlberg Health Monitoring and Promotion Program Study Group. $\gamma$-Glutamyltransferase as a risk factor for cardiovascular disease mortality: an epidemiological investigation in a cohort of 163,944 Austrian adults. Circulation $20051122130-2137$. (doi:10.1161/CIRCULATIONAHA.105.552547)

27 Kannel WB, Kannel C \& Paffenbarger RS. Heart rate and cardiovascular mortality: the Framingham study. American Heart Journal 1987113 1489-1494. (doi:10.1016/0002-8703 (87)90666-1)

28 Mensink GB \& Hoffmeister H. The relationship between resting heart rate and all-cause, cardiovascular and cancer mortality. European Heart Journal 199718 1404-1410.

29 Weise M, Mehlinger SL, Drinkard B, Rawson E, Charmandari E, Hiroi M, Eisenhofer G, Yanovski JA, Chrousos GP \& Merke DP. Patients with classic congenital adrenal hyperplasia have decreased epinephrine reserve and defective glucose elevation in response to high-intensity exercise. Journal of Clinical Endocrinology and Metabolism 200489 591-597. (doi:10.1210/jc.2003030634)

30 Riepe FG, Krone N, Krüger SN, Sweep FC, Lenders JW, Dötsch J, Mönig H, Sippell WG \& Partsch CJ. Absence of exerciseinduced leptin suppression associated with insufficient epinephrine reserve in patients with classic congenital adrenal hyperplasia due to 21-hydroxylase deficiency. Experimental and Clinical Endocrinology and Diabetes 2006114 105-110. (doi:10. 1055/s-2005-865836)

31 Green-Golan L, Yates C, Drinkard B, VanRyzin C, Eisenhofer G, Weise M \& Merke DP. Patients with classic congenital adrenal hyperplasia have decreased epinephrine reserve and defective glycemic control during prolonged moderate-intensity exercise. Journal of Clinical Endocrinology and Metabolism $2007 \mathbf{9 2}$ 3019-3024. (doi:10.1210/jc.2007-0493)

32 Völkl TM, Simm D, Dötsch J, Rascher W \& Dörr HG. Altered 24-hour blood pressure profiles in children and adolescents with classical congenital adrenal hyperplasia due to 21-hydroxylase deficiency. Journal of Clinical Endocrinology and Metabolism 2006 91 4888-4895. (doi:10.1210/jc.2006-1069)

33 Thilén A, Nordenström A, Hagenfeldt L, von Döbeln U, Guthenberg C \& Larsson A. Benefits of neonatal screening for congenital adrenal hyperplasia (21-hydroxylase deficiency) in Sweden. Pediatrics 1998101 E11. (doi:10.1542/peds.101.4.e11)

34 Williams RM, Deeb A, Ong KK, Bich W, Murgatroyd PR, Hughes IA \& Acerini CL. Insulin sensitivity and body composition in children with classical and nonclassical congenital adrenal hyperplasia. Clinical Endocrinology 201072 155-160. (doi:10. 1111/j.1365-2265.2009.03587.x)

35 Knorr D \& Hinrichsen de Lienau SG. Persistent obesity and short final height after corticoid overtreatment for congenital adrenal hyperplasia (CAH) in infancy. Acta Paediatrica Japonica 198830 (Supplement) 89-92.

Received 20 November 2010

Accepted 23 November 2010 